\title{
STUDENT PROJECT Horticultural protocols for experimental studies of eyebrights (Euphrasia, Orobanchaceae)
}

\author{
Max Richard Brown', Hannes Becher², Giles Laverack ${ }^{3}$ \& Alex David Twyford ${ }^{4}$
}

\begin{abstract}
Parasitic plants are particularly challenging to cultivate as the growth conditions must be suitable for the parasite, the host and their interaction. Here, we review our progress growing eyebrights (Euphrasia), a group of hemiparasitic plants found in diverse habitats in Britain and Ireland. We consider the protocols required to grow them under a range of conditions, including as unhosted seedlings in the laboratory, mature plants in pot trials and commercialscale quantities in cultivated fields, as well as the establishment of plants in the wild. We draw on recent research results from pot experiments, and also present new results from preliminary field trials and reciprocal transplant experiments in nature. We find that the growth conditions for Euphrasia must use cold stratification to break seed dormancy, use a suitable host species and manage the host to avoid competition, and mimic their natural environment in terms of free-draining soil and unshaded conditions. While Euphrasia can be successfully grown in different environments, more reliable protocols are required for establishing mature plants under natural conditions.
\end{abstract}

\section{Introduction}

Parasitic plants are a diverse group of approximately 4,500 species that are characterised by possessing a parasitic feeding organ called a haustorium that can attach and steal nutrients from a host plant (Nickrent, 2020). Some of the most familiar parasitic plants include the crop pest witchweed (Striga, Orobanchaceae), mistletoes such as Viscum album (Santalaceae), the common grassland wildflower yellow rattle (Rhinanthus, Orobanchaceae) and the species possessing the largest flower in nature, Rafflesia arnoldii (Rafflesiaceae) (Twyford, 2018). The diversity of parasitic plants, with parasitism described from 12 plant families (Westwood et al., 2010), is matched by the diversity of growing conditions necessary to succeed in cultivating these plants. Even related parasitic plant species can be found under contrasting conditions and it is important that these are mirrored in cultivation (Joel et al., 2013). There are also a number of specific horticultural issues associated with growing parasitic plants that must be overcome,

${ }^{1}$ Max Brown is a PhD student at the University of Edinburgh.

Address: Ashworth Laboratories, King's Buildings, Charlotte Auerbach Road, Edinburgh, EH9 3FL, UK.

${ }^{2}$ Hannes Becher is a postdoctoral researcher at the University of Edinburgh.

Address: as above.

${ }^{3}$ Giles Laverack is the Managing Director of Scotia Seeds.

Address: Mavisbank, Brechin, DD9 6TR, UK.

${ }^{4}$ Alex Twyford is a Lecturer in botany at the University of Edinburgh and a Research Associate at the Royal Botanic Garden Edinburgh. He is the corresponding author for this paper.

Address: Ashworth Laboratories, King's Buildings, Edinburgh, EH9 3FL, UK.

Email: Alex.Twyford@ed.ac.uk 
and the conditions must be suitable for the parasite, the host and their interaction. In particular, many parasitic plants (notably obligate parasites) require host-specific cues in order to germinate (Yoneyama et al., 2010), and almost all parasitic plants require a host in order to grow vigorously (Albrecht et al., 1999). Despite these issues, a wide variety of parasitic plants are cultivated (Pignone \& Hammer, 2016). Recently, the use of parasitic plants in ecological restoration has increased interest in their cultivation and seed production, making the dissemination of cultivation protocols particularly timely.

The genus Euphrasia (Orobanchaceae) contains approximately 263 species (Daniel Nickrent, pers. comm.) distributed throughout temperate areas of the northern and southern hemispheres, and in montane regions of tropical South East Asia (Gussarova et al., 2008). It includes both perennial and annual species (Yeo, 1973). Euphrasia are generalist hemiparasites, meaning they are photosynthetically competent and can grow without a host, but perform much better when grown with one of many potential hosts (grasses, forbs, legumes) (Yeo, 1964; Brown et al., 2020). We are currently developing Euphrasia as a study system for understanding plant parasitism, and for investigating evolutionary questions related to natural hybridisation, genome evolution and mating system diversity. There are 20 native British Euphrasia species, which show rich variation in habitat preference, associated species, ploidy (there are diploids and tetraploids) (Yeo, 1956; Wang et al., 2018) and mating system (there are selfing and outcrossing species) (French et al., 2005; Metherell \& Rumsey, 2018). Species of Euphrasia are known to hybridise extensively in the field and produce a diversity of hybrids as well as species of hybrid origin (Stace et al., 2015; Metherell \& Rumsey, 2018).

In this article, we describe our experience optimising horticultural protocols for growing British native eyebrights. This builds on the body of work by Peter Yeo during his time as a taxonomist at Cambridge University Botanic Garden. Yeo published extensively on the taxonomy and evolution of European Euphrasia (e.g. Yeo 1956, 1961, 1964, 1973). Many of his observations were made on plants he grew in cultivation, either from seeds or from turf containing Euphrasia he extracted from the wild. Here, we discuss the range of protocols for experimental growth studies under laboratory conditions, in pot trials, under field conditions and in the wild. We review our general experience and personal observations made while conducting a suite of experimental studies growing Euphrasia with different hosts (Brown et al., 2020; Brown et al., 2021; Becher et al., 2020), and also present preliminary results from field trials, and from reciprocal transplant experiments in the wild.

\section{General considerations for cultivating Euphrasia}

Most experimental work on plants focuses on species that are simple to grow, are small in size at maturity and rapidly complete their lifecycle, such as many model plant species like the thale-cress Arabidopsis thaliana (Wienkoop et al., 2010). British Euphrasia are also small annual plants suited to experimental manipulation, but require more specialised cultivation. Euphrasia seeds have dormancy, and cold treatment is required to induce germination (Yeo, 1961; Liebst, 2008). This seasonal cue is likely to be important in natural environments to ensure germination is initiated synchronously, at a suitable time in the spring (Rubin \& Friedman, 2018). In 
our experimental work, we have broken seed dormancy in one of two ways: leaving seeds outside over winter, or forcing germination in the fridge. The latter method can be achieved by storing seeds on damp tissue paper on sterile plates. In this case, only a couple of drops of water are needed, otherwise mould may grow. With these dormancy constraints, we have only ever grown one generation per year, although a shorter generation time may be possible under controlled conditions (see below).

\section{Seed germination rates in Euphrasia} are variable and often low (Yeo, 1964). We have found the germination success of wild-collected seeds to be around 40-50 per cent (Brown et al., 2020), though it can be as low as 20 per cent. The probability of germination depends on the condition of the seed. For example, in a small-scale test of E. arctica seed germination, we found 10 out of 20 seeds considered 'plump' successfully germinated, compared to 6 out of 20 in 'intermediate' condition, and none that were considered 'shrivelled' (Fig. 1). It is likely that the shrivelled seeds had been aborted by the parent plant, because of either developmental problems, genetic abnormalities or limited resources (Stephenson, 1981). In general, collections late in the season are likely to have the lowest germination success as most viable seeds will have dehisced. Seed cleaning by sieving and winnowing, or for larger quantities using machinery such as a gravity separator, can help to remove shrivelled or abnormally small seeds and subsequently improve germination rates. Euphrasia seeds should be dried (e.g. at room temperature for one week) prior to storage in the fridge. Seeds frozen at $-4{ }^{\circ} \mathrm{C}$ were also found to store well and survive for at least three years (Chapman et al., 2019). In general, germination is synchronous, with the majority of seeds in our outdoor pot experiments germinating in a two-week window in April. However, there are likely to be some differences between species (Fig. 2).

Euphrasia require a host for vigorous growth, and this requirement must be met within a few days of germination to ensure growth is not hindered (Wettstein, 1897; Yeo, 1961). Germinating Euphrasia seeds produce relatively large cotyledons and a robust hypocotyl, while the radicle is relatively small (Simpson, 1977). Root expansion occurs quickly, and there is notable root hair formation within a week. Euphrasia unable to find a host within the first two weeks often die, while some may remain small in stature above ground but develop an extensive below-ground root system questing for a host (Yeo, 1961). The choice of host species can have a dramatic influence on the survival of Euphrasia. For example, some fast-growing hosts that Euphrasia cannot attach to

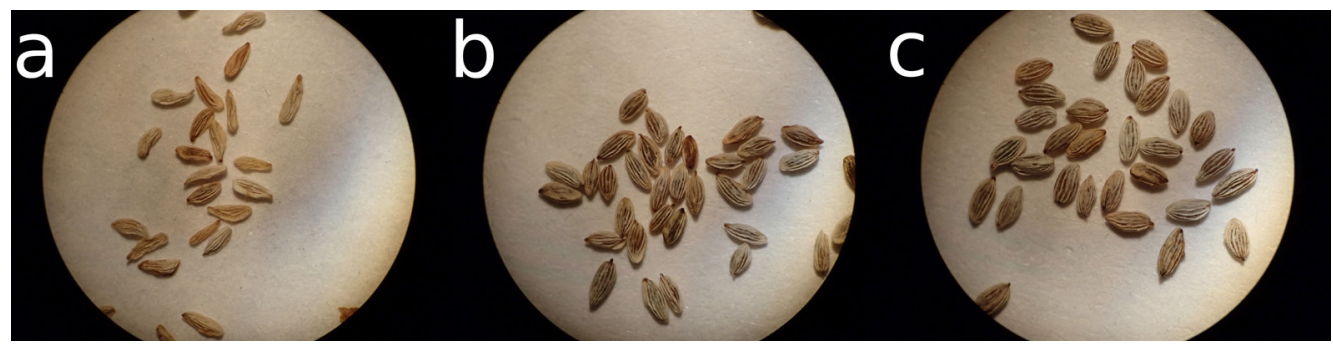

Fig. 1 Three categories of Euphrasia seed quality: (a) shrivelled; (b) intermediate; and (c) plump. The seeds are approximately $2 \mathrm{~mm}$ in length. Photos: Hannes Becher. 


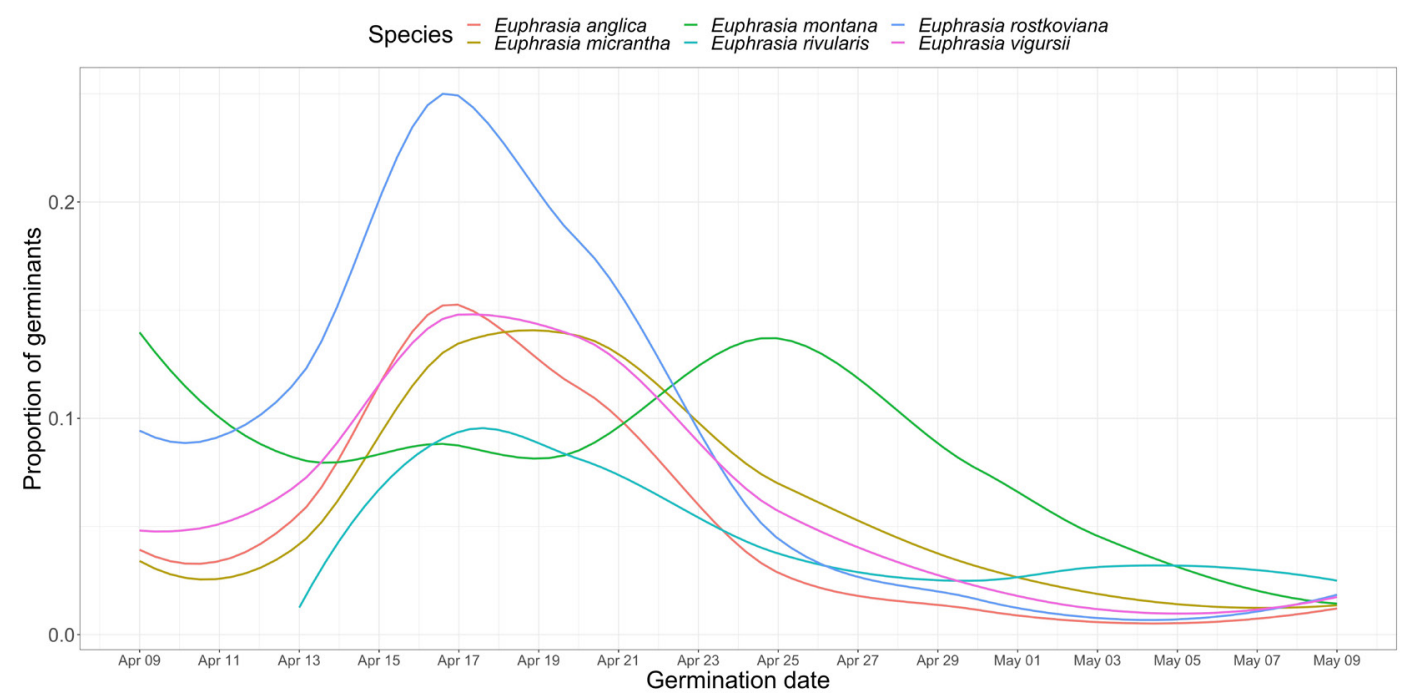

Fig. 2 Euphrasia seed germination profile at the Royal Botanic Garden Edinburgh. Plot shows germination of six Euphrasia species based on monitoring every two days in the spring of 2018, for the study of Brown et al. (2021).

compete with the Euphrasia seedling for light, and increase the probability of Euphrasia mortality. In general, leguminous or grass host species confer higher survival than forbs or woody plants.

In pots, a host can be introduced carefully after Euphrasia seeds germinate, with minimal disruption to the Euphrasia plant. Otherwise, the host seed can be sown at the same time as the Euphrasia seed. However, because Euphrasia seed germination is variable and often low ( $<50$ per cent), this approach wastes many host plants. Moreover, sowing hosts separately in the spring allows germination time to be controlled, whereas planting with Euphrasia in the autumn results in asynchronous host germination and growth, adding a confounding variable in controlled experimental studies. More generally, sowing Euphrasia into pre-existing vegetation is possible, however Euphrasia is a poor competitor and the vegetation must be sufficiently low or sparse for successful establishment (see Field trials below). Subsequently, as British Euphrasia are annual plants, all individuals die at the end of the season, which typically lasts until late September.

In cultivation and in the wild, Euphrasia may be attacked by a number of pests. The most serious are aphids (Aphididae), which attack the upper stem and leaves. In heavy infestations, leaves can fall off the plant, and in some cases aphid damage can be fatal. The effect of aphids can be alleviated by spraying with a soap solution, or if Euphrasia individuals are kept in glasshouses, by maintaining good air movement and ventilation. Another common pest is a species of rust, Coleosporium (Fig. 3), alternate host likely to be species of Pinus (Ellis \& Ellis, 1985), which is an alarming orange colour, though its effect on Euphrasia is not known. Lastly, some Lepidopteran caterpillar species in the genus Perizoma attack Euphrasia by spinning and eating the leaves (Fitter \& Peat, 1994).

\section{Laboratory conditions}

For detailed studies of plant development, it is often necessary to grow plants under 


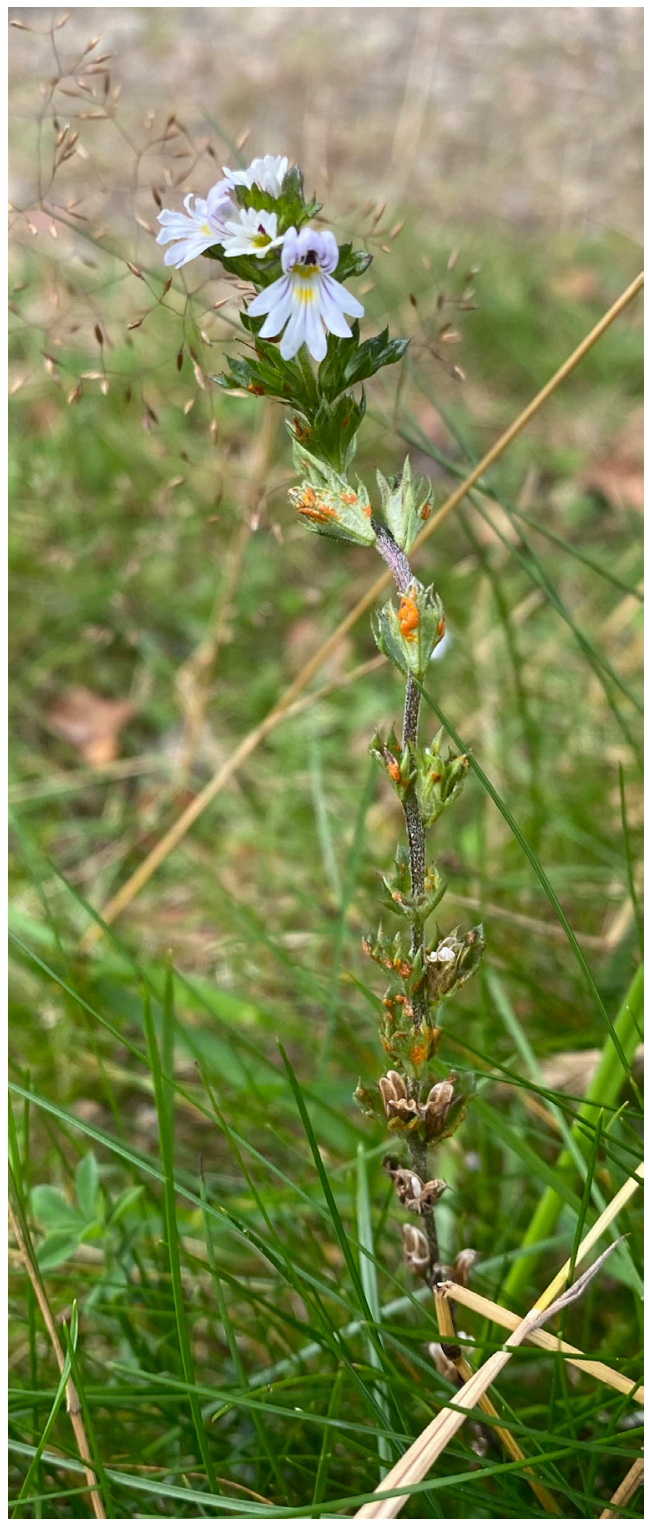

Fig. 3 Coleosporium sp. on Euphrasia (Pitlochry, Perthshire, UK, September 2020). Photo: Hannes Becher.

controlled laboratory conditions. For such studies, Euphrasia seeds can be readily germinated on moist filter paper under sterile conditions, using ethanol to sterilise petri dishes and seeds, and sealing the sterile dishes with tape to avoid contamination. Petri dishes should be maintained in a fridge at $4{ }^{\circ} \mathrm{C}$ until germination (no supplemental light is required). We have grown wild-collected E. arctica seeds in this way, with germination observed after a period of six weeks (Brown, personal observation). This sterile platebased method is suitable for obtaining young seedlings, as required for certain applications (such as young root samples for cytogenetic analysis), but further refinement is necessary to make this suitable for growing larger plants. For more detailed developmental studies plants can be grown on an artificial medium on sterilised plates. Seeds will germinate after approximately 10 days at $4{ }^{\circ} \mathrm{C}$ on $1 / 4$ Hoagland solution, a widely used hydroponic nutrient solution used to grow other parasitic plants (Delavault et al., 1998).

\section{Pot trials}

Growing Euphrasia in pots has the benefit of plants being in a substrate where they can form more natural host interactions than they would on an artificial medium in the laboratory. Pot trials are useful for common garden studies, where material of different provenance and/or from different species is grown under common conditions. Any phenotypic differences between individuals, populations and species which are observed under common conditions can be attributed to heritable (i.e. genetic or some epigenetic) differences (e.g. Riihimaki \& Savolainen, 2004). Reduced differentiation under common conditions relative to the wild, however, indicates that the phenotypic differences observed in nature were mainly due to environmental differences such as soil, herbivory or the available host plants. This kind of common garden experiment is used extensively in ecology, evolution and genetic research to investigate the effects of 'nature vs nurture'.

We have performed five experimental common garden studies with Euphrasia 
Table 1 Summary of Euphrasia common garden experiments conducted at the RBGE nursery.

\begin{tabular}{|c|c|c|c|c|}
\hline & Aim of experiment & Euphrasia species and hosts & $\begin{array}{l}\text { Growth } \\
\text { conditions }\end{array}$ & Reference \\
\hline 1 & $\begin{array}{l}\text { Understand } \\
\text { morphological } \\
\text { differences between } \\
\text { diverse Euphrasia } \\
\text { species }\end{array}$ & $\begin{array}{l}222 \text { individuals from } 11 \\
\text { Euphrasia taxa, grown with a } \\
\text { clover host }\end{array}$ & $\begin{array}{l}\text { Pot experiment in } \\
\text { a Hartley Botanic } \\
\text { Glasshouse, } 2016\end{array}$ & $\begin{array}{l}\text { Brown et al. } \\
(2020)\end{array}$ \\
\hline 2 & $\begin{array}{l}\text { Study how host species } \\
\text { impacts on Euphrasia } \\
\text { morphology }\end{array}$ & $\begin{array}{l}194 \text { individuals of } E \text {. arctica } \\
\text { on } 8 \text { different host species, } \\
\text { and without a host }\end{array}$ & $\begin{array}{l}\text { Pot experiment in } \\
\text { a Hartley Botanic } \\
\text { Glasshouse, } 2016\end{array}$ & $\begin{array}{l}\text { Brown et al. } \\
(2020)\end{array}$ \\
\hline 3 & $\begin{array}{l}\text { Quantify Euphrasia } \\
\text { performance and } \\
\text { survival with diverse } \\
\text { hosts }\end{array}$ & $\begin{array}{l}\text { 1,379 individuals of E. arctica } \\
\text { on } 45 \text { different hosts }\end{array}$ & $\begin{array}{l}\text { Pot experiment } \\
\text { in a Venlo } \\
\text { Glasshouse, } 2017\end{array}$ & $\begin{array}{l}\text { Brown et al. } \\
(2021)\end{array}$ \\
\hline 4 & $\begin{array}{l}\text { Investigate Euphrasia- } \\
\text { host interactions }\end{array}$ & $\begin{array}{l}1,259 \text { individuals from } \\
6 \text { different Euphrasia } \\
\text { populations on } 13 \text { different } \\
\text { hosts }\end{array}$ & $\begin{array}{l}\text { Pot experiment } \\
\text { in a Venlo } \\
\text { Glasshouse, } 2018\end{array}$ & $\begin{array}{l}\text { Brown et al. } \\
(2021)\end{array}$ \\
\hline 5 & $\begin{array}{l}\text { Investigate differences } \\
\text { between tetraploid } \\
\text { Euphrasia species from } \\
\text { an isolated island }\end{array}$ & $\begin{array}{l}2,124 \text { individuals from } 2 \\
\text { populations from each of } 3 \\
\text { Euphrasia species from Fair } \\
\text { Isle, Shetland, grown with } 12 \\
\text { host species }\end{array}$ & $\begin{array}{l}\text { Pot experiment in } \\
\text { an outside frame, } \\
2019\end{array}$ & $\begin{array}{l}\text { Becher et } \\
\text { al. (2020) }\end{array}$ \\
\hline
\end{tabular}

grown in pots at the Royal Botanic Garden Edinburgh (RBGE) nursery (see Table 1). All of the experiments involved germinating the seeds in pots outside in the bark-based substrate RBGE $1,{ }^{5}$ before (in the first four experiments) moving pots with seedlings to a greenhouse environment for the growing season.

The initial experiments aimed to study the growth patterns of different Euphrasia species, and the impact of different hosts and plants grown without a host (Brown et al., 2020). We found that the host species affected some Euphrasia traits (e.g. height),

\footnotetext{
${ }^{5}$ The substrate RBGE1 is a mix of organically derived material made by Melcourt Industries for and in collaboration with RBGE nursery staff. It consists of 50 per cent Growbark pine (finely milled pine bark), 35 per cent Sylvafibre and 15 per cent composted green material.
}

but not others (e.g. nodes to flower), and that certain Euphrasia species overlapped in many traits (e.g. the related E. arctica, E. confusa and $E$. nemorosa), while others were relatively distinct (e.g. E. micrantha and other Euphrasia species tested). In the third experiment, we measured the same species, E. arctica, but this time grown on a wider range of different host species. We found that survival and fitness varied greatly between Euphrasia on different hosts. In 2018, we measured for the first time the fitness of different Euphrasia species on a range of different hosts, in order to investigate host-parasite interactions in specific Euphrasia-host combinations. The fifth experiment investigated adaptation and morphology in species from different habitats on the isolated island of Fair Isle, Shetland (Scotland) (Becher et al., 2020). Here our aim 
was to investigate whether the species are morphologically distinct when grown under standardised conditions, using grassland $E$. arctica, coastal E. foulaensis and heathland E. micrantha. We found that they did retain different morphologies in the common garden, albeit to a lesser extent than in their natural environment.

All 5 experiments aimed for at least 30 pots of each Euphrasia population-host combination and allowed for approximately 50 per cent germination success. A single seed was planted in the centre of the pot, with this placement helping to distinguish it from any contaminant weed seeds. Nine-cm planting pots were filled with the potting mix. After sowing, plants were lightly top-dressed with sieved soil and moved to an outside seed frame where they remained until germination (Fig. 4a). Careful introduction of a host plant is critical to establish a connection between Euphrasia and the host. Host seeds were sown into trays filled with RGBE1 potting mix in February. In April, we transplanted young host plants $(<2$ weeks post-germination) into a pot containing Euphrasia. The transplanted individual is placed equidistant between the Euphrasia individual and one of the four corners of the pot. In common garden trials with many plants, this allowed us to keep a consistent distance between the Euphrasia and the host plant so there was no effect of distance to host. Placement of a host too close to the Euphrasia could lead to either very early attachment (which would be beneficial) or high levels of competition (which would be detrimental). Pots containing Euphrasia and host were then moved to their final growing conditions: the glasshouse or outside. During the course of the summer host plants had to be trimmed to avoid shading the Euphrasia

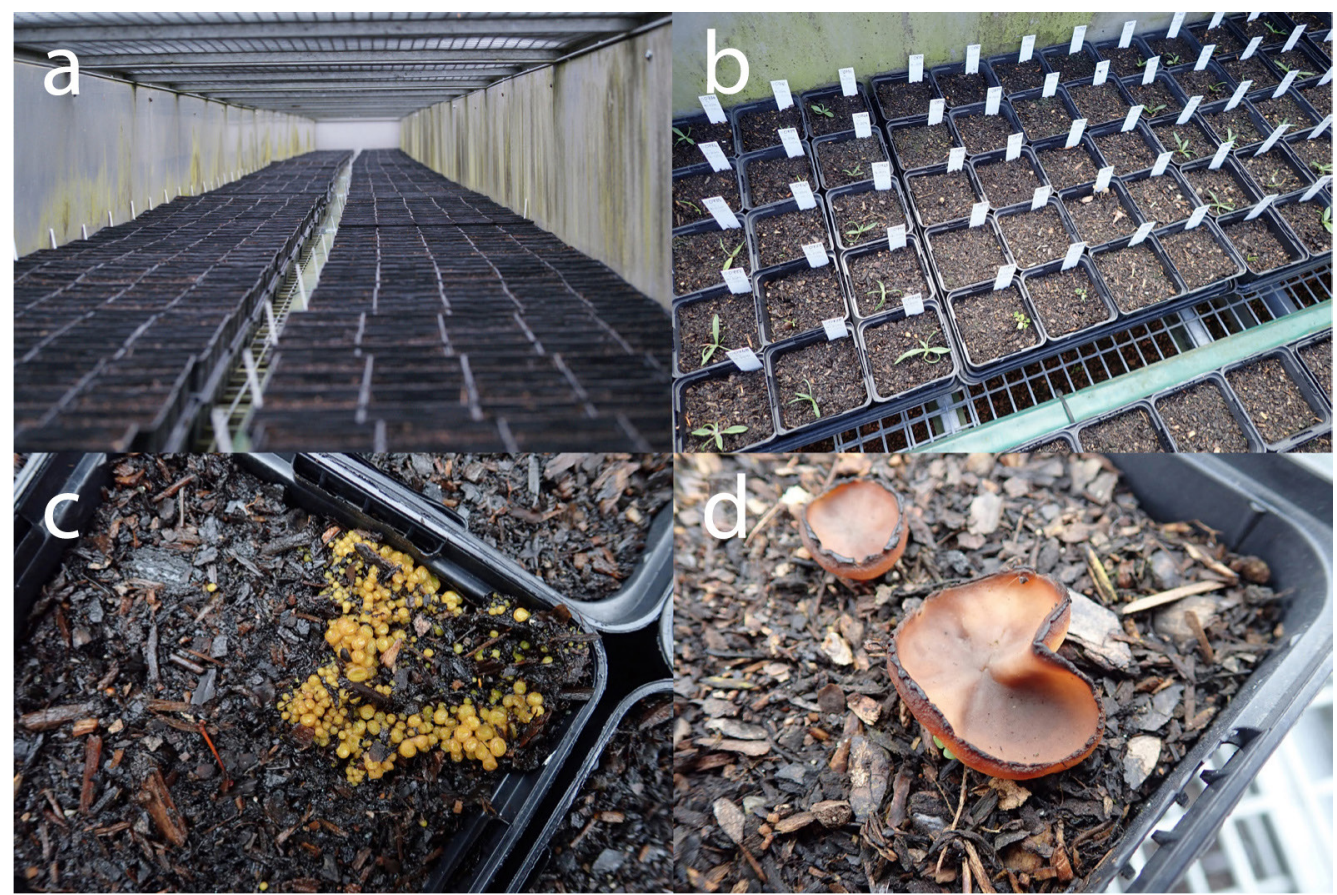

Fig. 4 Growth frames at the RBGE nursery used for Euphrasia germination and the Fair Isle Euphrasia experiment of Becher et al. (2020). Panels (a) and (b) show growth frame with pots in trays of 20. Panels (c) and (d) show fungal growth on the soil surface after waterlogging following the extremely wet spring of 2019. All photos: Hannes Becher. 
and to avoid spreading species rooting in adjacent pots. This was most important for species with a prostrate or spreading growth habit, such as vigorously growing clover (Trifolium repens). Pots were randomised monthly to minimise block effects (e.g. plants on one bench growing better than others). We checked daily to see if any Euphrasia had newly flowered. All trait measurements were made the day of first flowering as this is a standardised time point allowing comparisons between individuals, while fitness measures were made throughout the season.

Host species selection is crucial for vigorous Euphrasia growth; without a host Euphrasia grow poorly, remain small and are unlikely to flower (Brown et al., 2020). We routinely used clover as a host in our initial experiments, though further experiments have revealed other legumes such as Lotus corniculatus are even better hosts (Brown et al., 2021). Plantago lanceolata is a good choice of forb, and Cynosorus cristatus a suitable grass that confers vigorous Euphrasia growth. Seed provenance is also important, with commercial seed stocks more likely to be genetically uniform and thus expected to produce more even Euphrasia growth. Genetic diversity in wild-collected seeds may produce uneven but more representative growth. In the Fair Isle Euphrasia experiment, wild-collected seeds were used as well as cuttings of wild-collected heather (Calluna vulgaris) and juniper (Juniperus communis). The use of more diverse hosts, particularly those with different soil requirements (such as acid-loving heathers), is likely to require a different potting medium for optimal host growth.

Our experimental studies have tested a range of growing conditions. The first two experiments used an older Hartley wooden-framed glasshouse, where there was relatively high mortality and issues with flower buds aborting due to high glasshouse temperatures on warm summer days. The second two experiments used a new Venlo Glasshouse, which is a controlled multi-span growing house that is better ventilated and climatically controlled. Finally, for the fifth experiment the whole study was conducted in an outside frame (Fig. 4) which has metal sides that help prevent damage by animals or wind. While there were benefits to growing plants outside (less vigorous growth similar to that seen in the wild), these plants grew relatively poorly, due to the partial shade caused by the sides of the frame. We also found the pots tended to become waterlogged, which created problems after the extended wet periods encountered in the spring of 2019. This was less of a problem in the glasshouse, where watering could be more easily controlled. In future, we plan to conduct experiments outside in dedicated frames with minimal shading, and adapt the potting substrate to be able to drain more freely.

Regardless of the growing conditions, watering has proven necessary to prevent pots drying out. Watering was done when required rather than as a matter of routine. We have found watering by hand to be more reliable for experimental work than automated irrigation, which can be patchy and may lead to uneven growth. Euphrasia favours drier over damper growing conditions, although this sometimes resulted in sub-optimal conditions for the hosts. Supplementary feeding proved necessary for vigorous Euphrasia growth in small pots of nutrient-poor RBGE1. The feeding regime began in May. When Euphrasia flowered, feeding was increased from fortnightly to weekly. Liquid feed was diluted at 1.5 per cent using a Dosatron ${ }^{\oplus}$ injector and applied when 
watering with a fine rose. The vigour of some of the hosts visibly improved after feeding, while feeding also promoted Euphrasia growth and prevented chlorosis. While feeding is necessary for optimal growth, we plan to test a reduced feeding regime in the future to better mimic natural soil conditions.

Pot experiments, particularly those conducted outside, require regular weeding. Special attention was given to weeding at the start of the season, before Euphrasia germinated, to avoid plants parasitising weeds. Mosses and liverworts were also removed when they threatened to smother Euphrasia. To avoid disturbing the roots of either the Euphrasia or host, all weeding was done with tweezers.

\section{Field trials}

The effect that parasitic plants have in reducing the vigour of surrounding vegetation is often exploited commercially. Parasitic yellow rattle (Rhinanthus minor) is a common species in many natural and semi-natural plant communities and is widely grown in meadows, reducing the need for mowing and maintenance (Westbury \& Dunnett, 2007; Ameloot et al., 2005). Euphrasia, as a related hemiparasite, could be used for similar purposes, with the wide habitat range of Euphrasia species making it potentially useful and appropriate in habitats unsuitable for Rhinanthus.

To produce seeds for large-scale planting, Euphrasia has to be cultivated on a field scale. In a collaboration with Scotia Seeds, ${ }^{6}$ field plots were set up with a view to understanding the feasibility of cultivating Euphrasia at scale. To do this a well-established protocol for cultivating Rhinanthus minor was adapted for Euphrasia. Previous attempts to produce crops by introducing Euphrasia seeds into established grass following scarification (the Rhinanthus approach) had failed, possibly due to competition from grasses. Therefore, field trials of Euphrasia were attempted in the season of 2018/2019 using a modified protocol. Two 24-m plots of cleared bare soil were planted with E. arctica seeds of two different provenances at 500 seeds per metre square $(0.625 \mathrm{~g})$, and with four different host treatments at $2 \mathrm{~g}$ per metre square. The host species used were Lotus corniculatus (bird's foot trefoil), Cynosorus cristatus (crested dog's tail), Plantago lanceolata (ribwort plantain) and Mavisbank Meadow Mix (a mix of over seventeen species of herbs and six species of grass). ${ }^{7}$ Plants were given minimal maintenance - plots were not watered, and spot weeding was carried out to remove any vigorous weeds that may have competed for resources.

Preliminary results indicate that cultivation of Euphrasia arctica on a field scale yields vigorous plants, at least $20 \mathrm{~cm}$ tall (Fig. 5). Plants of this height typically produce 300 flowers and therefore around 1,800 seeds (assuming six viable seeds per capsule). For harvesting efficiency, it is recommended that either Lotus corniculatus or Plantago lanceolata is used as a host, as grass species cause Euphrasia to form flexuous stem bases, which are difficult to harvest. P. lanceolata seeds in particular are easily separated from Euphrasia seeds, making this pairing a practical combination to produce pure Euphrasia seeds without contamination of other species, an important consideration in seed production. Control of annual weeds will be an important part of any field production protocol, and sowing in rows may be helpful. Using this approach, E. arctica could be 


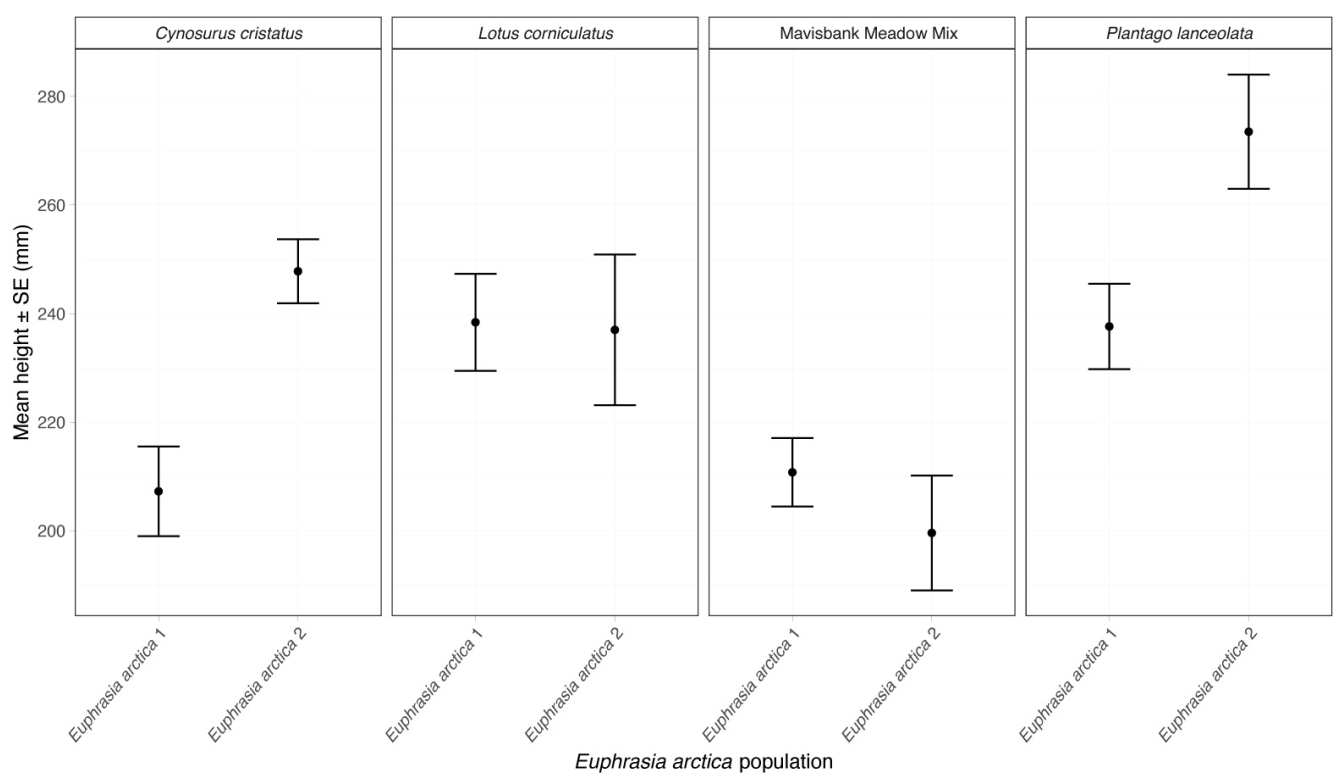

Fig. 5 Mean heights and standard errors of Euphrasia arctica populations grown in experimental field plots at Scotia Seeds, Angus (Scotland). Each panel shows the growth of Euphrasia on a given host plant(s). Measurements were pooled from three replicate plots for E. arctica genotype 1 and one plot for E. arctica genotype 2 (from North Berwick and Inverkeithing (both Scotland), respectively).

managed on a field scale and give suitable yields for seed production.

\section{Reciprocal transplant experiments}

While the protocols outlined above emulate aspects of natural conditions, some circumstances may require plants to be grown in the wild, such as when conducting evolutionary and ecological studies of local adaptation. Local adaptation is the situation where plants from different origins perform best at their 'home' source site (Blanquart et al., 2013). The gold standard for testing for local adaptation is the reciprocal transplant experiment, which assesses the performance of plant populations from two or more different sites (Kawecki \& Ebert, 2004). Plants from each population are simultaneously grown at both their home site and the 'away' site. Reciprocal transplant experiments have recently been conducted with hemiparasitic Rhinanthus minor, focusing on adaptation to elevation differences between sites (Hargreaves \& Eckert, 2019), and showing the feasibility of this approach for hemiparasitic plant research. We have conducted a reciprocal transplant experiment to assess local adaptation to site conditions and hosts in Fair Isle Euphrasia, in parallel with the pot experiment described above.

Conducting a transplant experiment in the wild with hemiparasitic plants brings unique challenges. Unlike other transplant experiments, clearing all local vegetation is not usually an option, as local hosts are required. However, precautions must be taken to minimise contamination with any local Euphrasia in the soil seedbank. As such, we filled small planting holes with a planting medium known to be free of other Euphrasia seeds, but where root growth is not impeded, so Euphrasia could attach to surrounding hosts. A pilot experiment conducted near Inverkeithing with inflated 'Jiffy' peat pellets sunk into tight-fitting holes (Fig. 6) proved 


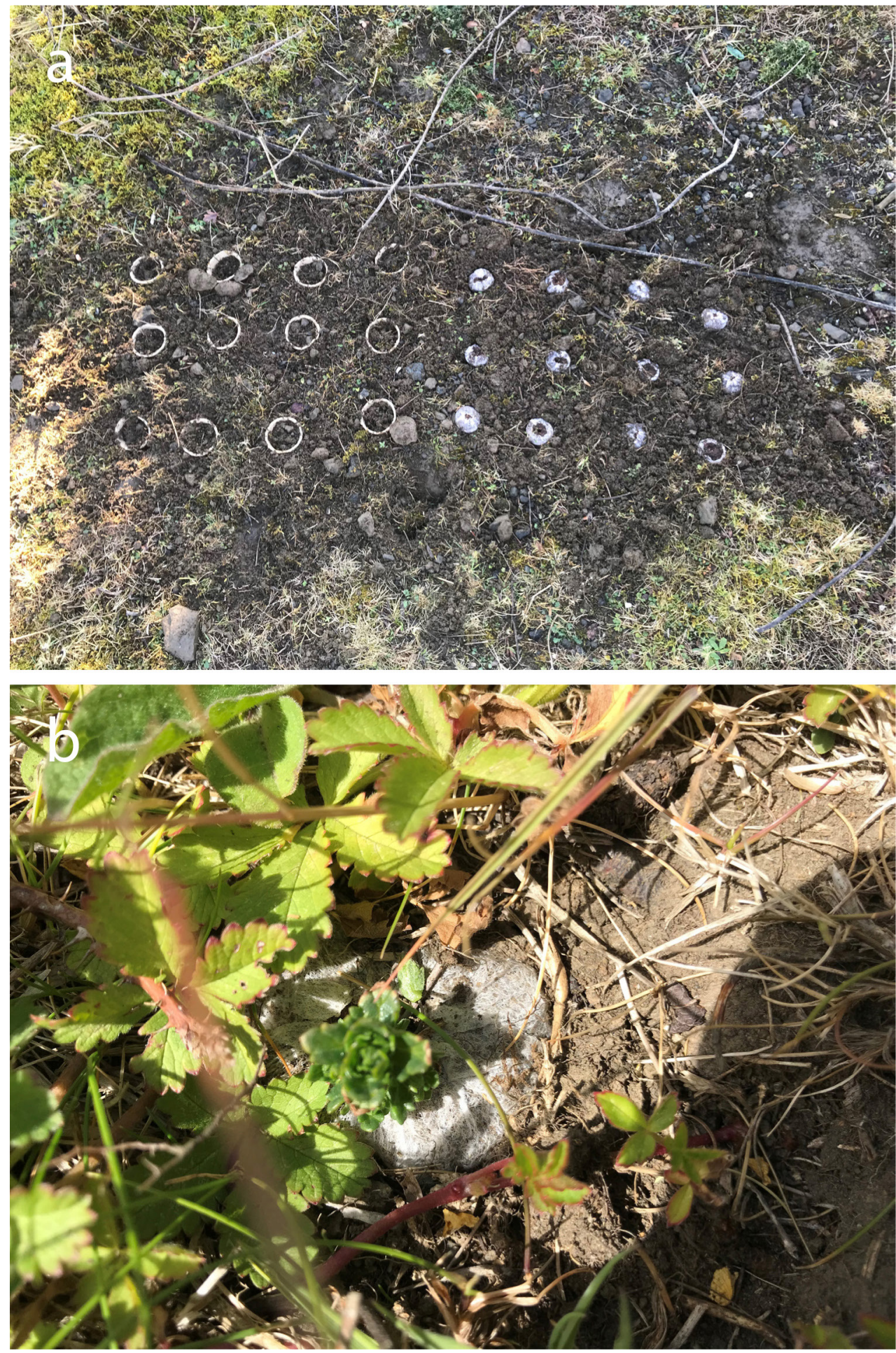

Fig. 6 Growing Euphrasia inside expandable 'Jiffy' pellets planted in a field site at Inverkeithing. (a) shows a planting array of pellets in the autumn, (b) shows an establishing seedling in the spring. After four months in the ground, the pellet's outer mesh showed no sign of decomposition. Photos: Alex Twyford. 
unsuccessful. The outer mesh of the pellets did not decompose within the field season, and many peat pellets were disturbed or displaced (Becher, personal observation). Instead, in the final experiment on Fair Isle, small holes in the ground were filled with John Innes No. 1 compost and a Euphrasia seed was subsequently added to each hole.

Euphrasia seeds from two populations of each of the three species were used both for a standardised common garden study at RBGE (see above, and Becher et al., 2020) and in a preliminary reciprocal transplant experiment. The transplant experiment aimed to test whether species germinate better in their home site rather than in a novel environment. We set up four transplant sites on Fair Isle, one in grassland, one in heathland and two at the coast. Each site comprised eight blocks, with each block comprising seventy-two planting holes. Each block was split into six sub-blocks (of twelve planting holes), one for each provenance, with Euphrasia seeds being assigned at random. Germination success the following May differed considerably between habitats and genotypes (Table 2). Overall, home or away sites had no significant effect in generalised linear models ( $p=0.497)$ and thus there was no general sign of local adaptation for germination across the experiment. There were, however, different results for individual species. Grassland $E$. arctica germinated better on average in away sites than in home sites (difference 10 per cent, $p=0.003$ ), while coastal $E$. foulaensis germinated better at home sites (difference 12 per cent, $p<0.001)$. For E. micrantha, the difference in germination between sites was not significant $(p=0.468)$. As such, Euphrasia species differ in their germination responses, but in a complex manner. The lack of a simple signal of local adaptation (e.g. home-site superiority) is not entirely surprising, especially given the small spatial scale of our experiment, as well as the nature of site differences (e.g. sites differ in multiple aspects such as soil, exposure and vegetation).

While in many respects this type of experiment in the wild provides the most natural setting, it comes with extensive challenges. For example, some substrates (such as heathland) are hard to dig, re-finding individual Euphrasia plants can be difficult and germination in natural conditions is very

Table 2 Germination of Euphrasia species in a reciprocal transplant experiment on Fair Isle.

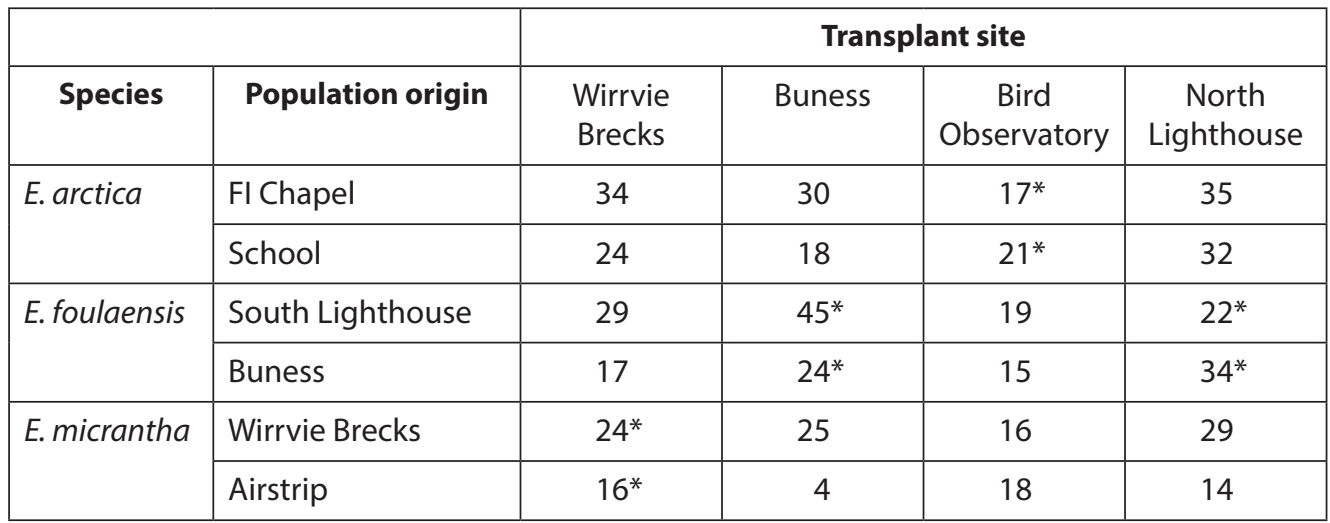

The numbers indicate successful germination from 72 planting holes per genotype and site. Asterisks ${ }^{*}$ ) indicate where a genotype was grown in its home habitat. Statistical significance was calculated using generalised linear models with a binomial error distribution in $\mathrm{R}$ (R Core Team, 2013), and with marginal differences calculated using the emmeans package (Lenth, 2020). 
patchy. In the Fair Isle experiment, attrition at each stage of establishment, coupled with surrounding vegetation growth and local germination of Euphrasia (not from the experimental setup), prevented us following long-term plant survival and growth. Despite these issues, it is still possible to carry out these kinds of experiments in natural settings, with trial-and-error to optimise methods, large sample sizes for plant recovery and statistical robustness, and careful monitoring required for success.

\section{Conclusions and future directions}

The genus Euphrasia represents an excellent study system to investigate the evolution of parasitism, the importance of natural hybridisation and the role of mating system variation. Euphrasia can easily be brought into cultivation in petri dishes in the lab, and in pots both in the glasshouse and outside. Euphrasia can be grown on many different species of host plant, making it an ideal system to investigate parasite-host interactions. Field trials have been met with success on a commercial scale, however reciprocal transplant experiments in the wild are difficult and these protocols require further optimisation. In summary, key considerations when growing Euphrasia are:

- $\quad$ Seed stratification is essential for germination. This can be simulated with artificial cold or plants can be overwintered outside.

- Unsorted wild-collected seeds have a low germination rate of around 50 per cent. The best germination rates are achieved from late summer collections made prior to seed dehiscence, followed by seed sorting and cold storage.

- Relatively few plant species are good hosts that confer substantial growth benefits to Euphrasia. Good hosts include many legumes, as well as Plantago lanceolata and Cynosorus cristatus.

- Euphrasia kept in pots outside should not be shaded, while those under glass require ventilation to prevent plants overheating and aborting developing buds.

- Euphrasia is less competitive than Rhinanthus in dense grassland swards. As such, established vegetation may need to be cleared for successful establishment.

There are many possibilities for future research building on these protocols. The cultivation of plants under laboratory conditions will allow developmental studies to investigate haustorium formation and the attachment of Euphrasia to different host plants (as has been done in Rhinanthus; see Rumer et al., 2007), and to generate contaminant-free tissue samples for genomic sequencing to understand the genes that cause parasitism (Yang et al., 2015). Common garden experiments will be used to investigate hemiparasite-host below-ground interactions, and to test whether Euphrasia has host preferences. Further large-scale reciprocal transplant experiments should be performed to understand the extent and nature of local adaptation in the genus. Trials to identify the best methods for establishing Euphrasia in ecological restoration and seed quality and storage work would be useful for seed production and use in restoration.

\section{Acknowledgements}

The authors thank RBGE horticultural staff, particularly Natacha Frachon, and Gavin Powell for their monumental efforts to bring Euphrasia species into cultivation. We also thank Chris Metherell for identifying Euphrasia specimens, Huiting Zhang, Claude dePamphilis and Paula Ralph for help 
cultivating Euphrasia on sterile plates, and Nick Riddiford for help with research on Fair Isle. Research on Euphrasia is funded by NERC grants (NE/R010609/1; NE/L011336/1;NE/ N006739/1) awarded to A.D. Twyford. The experimental work was performed at RBGE, which is funded from the Scottish Government's Rural and Environment Science and Analytical Services Division (RESAS).

\section{References}

\author{
ALBRECHT, H., YODER, J.I. \& PHILLIPS, D.A. \\ (1999). Flavonoids promote haustoria formation \\ in the root parasite Triphysaria versicolor. Plant \\ Physiology, 119(2): 585-591. doi: https://doi. \\ org/10.1104/pp.119.2.585
}

\section{AMELOOT, E., VERHEYEN, K. \& HERMY, M. (2005). Meta-analysis of standing crop reduction by Rhinanthus spp. and its effect on vegetation structure. Folia Geobotanica, 40: 289-310. doi: 10.1007/BF02803241}

BECHER, H., BROWN, M., POWELL, G., METHERELL, C., RIDDIFORD, N.J. \& TWYFORD, A.D. (2020). Maintenance of species differences in closely related tetraploid parasitic Euphrasia (Orobanchaceae) on an isolated island. Plant Communications, 1(6): 100105. doi: https://doi. org/10.1016/j.xplc.2020.100105

BLANQUART, F., KALTZ, O., NUISMER, S.L. \& GANDON, S. (2013). A practical guide to measuring local adaptation. Ecology Letters, 16(9): 1195-1205. doi: https://doi.org/10.1111/ele.12150

BROWN, M.R., FRACHON, N., WONG, E.L.Y., METHERELL, C. \& TWYFORD, A.D. (2020). Life history evolution, species differences, and phenotypic plasticity in hemiparasitic eyebrights (Euphrasia). American Journal of Botany, 107(3): 456-465. doi: https://doi.org/10.1002/ajb2.1445

BROWN, M.R., MOORE, P.G.P. \& TWYFORD, A.D. (2021). Performance of generalist hemiparasitic Euphrasia across a phylogenetically diverse host spectrum. bioRxiv, 2021.03.25.436816. doi: https:// doi.org/10.1101/2021.03.25.436816

CHAPMAN, T., MILES, S. \& TRIVEDI, C. (2019). Capturing, protecting and restoring plant diversity in the UK: RBG Kew and the Millennium Seed Bank. Plant Diversity, 41(2): 124-131. doi: https://doi. org/10.1016/j.pld.2018.06.001

DELAVAULT, P., ESTABROOK, E., ALBRECHT, H., WROBEL, R. \& YODER, J.I. (1998). Host-root exudates increase gene expression of asparagine synthetase in the roots of a hemiparasitic plant Triphysaria versicolor (Scrophulariaceae). Gene, 222(2): 155-162. doi: https://doi.org/10.1016/ S0378-1119(98)00502-2

ELLIS, M.B. \& ELLIS, J.P. (1985). Microfungi on Land Plants. An Identification Handbook. Croom Helm Ltd, Beckenham.

FITTER, A.H. \& PEAT, H.J. (1994). The ecological flora database. Journal of Ecology, 82(2): 415-425. doi: https://doi.org/10.2307/2261309

FRENCH, G.C., ENNOS, R.A., SILVERSIDE, A.J. \& HOLLINGSWORTH, P.M. (2005). The relationship between flower size, inbreeding coefficient and inferred selfing rate in British Euphrasia species. Heredity, 94(1): 44-51. doi: https://doi.org/10.1038/ sj.hdy. 6800553

GUSSAROVA, G., POPP, M., VITEK, E. \& BROCHMANN, C. (2008). Molecular phylogeny and biogeography of the bipolar Euphrasia (Orobanchaceae): recent radiations in an old genus. Molecular Phylogenetics and Evolution, 48(2): 444-460. doi: https://doi.org/10.1016/j. ympev.2008.05.002

HARGREAVES, A.L. \& ECKERT, C.G. (2019). Local adaptation primes cold-edge populations for range expansion but not warming-induced range shifts. Ecology Letters, 22: 78-88. doi: https://doi. org/10.1101/259879

JOEL, J., GRESSEL, J. \& MUSSELMAN, L. (2013). Parasitic Orobanchaceae. Springer, Berlin.

KAWECKI, T.J. \& EBERT, D. (2004).

Conceptual issues in local adaptation. Ecology Letters, 7: 1225-1241. doi: https://doi. org/10.1111/j.1461-0248.2004.00684.x

LENTH, V.R. (2020). emmeans: Estimated Marginal Means, aka Least-Squares Means. R package version 1.5.3. Available online: https://CRAN.R-project.org/ package $=$ emmeans (accessed December 2020).

LIEBST, B. (2008). Do they really hybridize? A field study in artificially established mixed populations of Euphrasia minima and E. salisburgensis (Orobanchaceae) in the Swiss Alps. Plant 
Systematics and Evolution, 273(3-4): 179-189. doi: https://doi.org/10.1007/s00606-008-0010-6

METHERELL, C. \& RUMSEY, F. (2018). Eyebrights (Euphrasia) of the UK and Ireland. Botanical Society of Britain and Ireland, Bristol.

NICKRENT, D.L. (2020). Parasitic angiosperms: how often and how many? Taxon, 69(1): 5-27. doi: https://doi.org/10.1002/tax.12195

PIGNONE, D. \& HAMMER, K. (2016). Parasitic angiosperms as cultivated plants? Genetic Resources and Crop Evolution, 63(7): 1273-1284. doi: https:// doi.org/10.1007/s10722-016-0416-x

$R$ CORE TEAM (2013). R: A language and environment for statistical computing. $R$ Foundation for Statistical Computing, Vienna. Available online: http://www.R-project.org (accessed December 2020).

RIIHIMAKI, M. \& SAVOLAINEN, O. (2004). Environmental and genetic effects on flowering differences between northern and southern populations of Arabidopsis lyrata (Brassicaceae). American Journal of Botany, 91(7): 1036-1045. doi: https://doi.org/10.3732/ajb.91.7.1036

RUBIN, M.J. \& FRIEDMAN, J. (2018). The role of cold cues at different life stages on germination and flowering phenology. American Journal of Botany, 105(3): 749-759. doi: https://doi. org/10.1002/ajb2.1055

RUMER, S., CAMERON, D.D., WACKER, R., HARTUNG, W. \& JIANG, F. (2007). An anatomical study of the haustoria of Rhinanthus minor attached to roots of different hosts. Flora, 202(3): 194-200. doi: https://doi.org/10.1016/j.flora.2006.07.002

SIMPSON, M.J.A. (1977). Fruit characters and seed germination of Euphrasia disperma Hook f., New Zealand Journal of Botany, 15: 181-183. doi: https:// doi.org/10.1080/0028825X.1977.10429621

STACE, C.A., PRESTON, C.D. \& PEARMAN, D. (2015). Hybrid Flora of the British Isles. Botanical Society of Britain \& Ireland, Bristol.

STEPHENSON, A.G. (1981). Flower and fruit abortion - proximate causes and ultimate functions. Annual Review of Ecology and Systematics, 12: 253-279. doi: https://doi.org/10.1146/annurev. es.12.110181.001345

TWYFORD, A.D. (2018). Parasitic plants. Current Biology, 28: R857-R859. doi: https://doi. org/10.1016/j.cub.2018.06.030
WANG, X., GUSSAROVA, G., RUHSAM, M., DE VERE, N., METHERELL, C., HOLLINGSWORTH, P.M. \& TWYFORD, A.D. (2018). DNA barcoding a taxonomically complex hemiparasitic genus reveals deep divergence between ploidy levels but lack of species-level resolution. AoB Plants, 10: ply026. doi: https://doi.org/10.1093/aobpla/ply026

WESTBURY, D.B. \& DUNNETT, N.P. (2007). The impact of Rhinanthus minor in newly established meadows on a productive site. Applied Vegetation Science, 10(1): 121-129. doi: https://doi. org/10.1111/j.1654-109X.2007.tb00510.x

WESTWOOD, J.H., YODER, J.I., TIMKO, M.P. \& DEPAMPHILIS, C.W. (2010). The evolution of parasitism in plants. Trends in Plant Science, 15: 227-235. doi: https://doi.org/10.1016/j. tplants.2010.01.004

WETTSTEIN, R. VON. (1897). Zur Kenntniss der Ernährunsverhälnisse von Euphrasia Arten. Österreichische botanische Zeitschrift, 47: 319-324.

WIENKOOP, S., BAGINSKY, S. \& WECKWERTH, W. (2010). Arabidopsis thaliana as a model organism for plant proteome research. Journal of Proteomics, 73(11): 2239-2248. doi: https://doi.org/10.1016/j. jprot.2010.07.012

YANG, Z.Z., WAFULA, E.K., HONAAS, L.A., ZHANG, H.T., DAS, M., FERNANDEZ-APARICIO, M., HUANG, K., BANDARANAYAKE, P.C.G., WU, B., DER, J.P., CLARKE, C.R., RALPH, P.E., ET AL. (2015). Comparative transcriptome analyses reveal core parasitism genes and suggest gene duplication and repurposing as sources of structural novelty. Molecular Biology and Evolution, 32: 767-790. doi: https://doi.org/10.1093/molbev/msu343

YEO, P. (1964). The growth of Euphrasia in cultivation. Watsonia, 6(1): 1-24.

YEO, P.F. (1956). Hybridisation between diploid and tetraploid species of Euphrasia. Watsonia, 3: 253-269.

YEO, P.F. (1961). Germination, seedlings, and the formation of haustoria in Euphrasia. Watsonia, 5: 11-22.

YEO, P.F. (1973). The Azorean species of Euphrasia. Boletim do Museu de História Natural do Funchal, 17: 74-83.

YONEYAMA, K., AWAD, A.A., XIE, X.N. \&

TAKEUCHI, Y. (2010). Strigolactones as germination stimulants for root parasitic plants. Plant and Cell Physiology, 51(7): 1095-1103. doi: https://doi.org/10.1093/pcp/pcq055 
